Loma Linda University

TheScholarsRepository@LLU: Digital Archive of Research, Scholarship \& Creative Works

Loma Linda University Electronic Theses, Dissertations \& Projects

8-1980

\title{
Distribution of Maternal and Fetal Blood Flow within Cotyledons of the Sheep Placenta
}

Gordon G. Power

P. Steven Dale

Paul S. Nelson

Follow this and additional works at: https://scholarsrepository.llu.edu/etd

Part of the Medical Biomathematics and Biometrics Commons

\section{Recommended Citation}

Power, Gordon G.; Dale, P. Steven; and Nelson, Paul S., "Distribution of Maternal and Fetal Blood Flow within Cotyledons of the Sheep Placenta" (1980). Loma Linda University Electronic Theses, Dissertations \& Projects. 1194.

https://scholarsrepository.llu.edu/etd/1194

This Thesis is brought to you for free and open access by TheScholarsRepository@LLU: Digital Archive of Research, Scholarship \& Creative Works. It has been accepted for inclusion in Loma Linda University Electronic Theses, Dissertations \& Projects by an authorized administrator of TheScholarsRepository@LLU: Digital Archive of Research, Scholarship \& Creative Works. For more information, please contact scholarsrepository@llu.edu. 


\begin{abstract}
DISTRIBUTION OF MATERNAL AND FETAL BLOOD FLOW WITHIN COTYLEDONS OF THE SHEEP PLACENTA

by
\end{abstract}

Gordon G. Power, P. Steven Dale, and Paul S. Nelson

These studies explore the distribution of blood flow among small samples of placental tissue. Labeled microspheres $(14 \pm 1 \mu \mathrm{m})$ were injected into the left ventricle of six unanesthetized ewes and into the jugular vein of the fetus in utero. A total of 3,576 samples weighing 31. \pm 11 . (S.D.) mg were taken from seventeen cotyledons and counted for flow labels. Maternal and fetal flow within the cotyledons were both normally distributed with standard deviations of $44 \%$. The maternal/ fetal flow ratio was less than 0.5 in $9 \%$ of the cotyledon, between 0.5 and 1.5 in $70 \%$, and greater than 1.5 in $21 \%$. Errors due to the method were estimated to contribute less than $10 \%$ of the flow variances. Maternal and fetal flows were significantly correlated $(r=0.57, p<.001)$. Spatial flow patterns were visualized using computerized image processing. The distribution of maternal and fetal flow may be a sensitive determinant of water transfer, and the distribution of their ratio explains about $50 \%$ of the uterine-umbilical venous oxygen tension gradient. Analysis of the correlation between samples vs. the distance separating them suggested a weight of roughly $125 \mathrm{mg}$ for hypothetical placental regulatory units. 
LOMA LINDA UNIVERSITY

Graduate School

DISTRIBUTION OF MATERNAL AND FETAL BLOOD FLOW WITHIN COTYLEDONS OF THE SHEEP PLACENTA

by

Gordon G. Power, P. Steven Dale, and Paul S. Nelson

A Manuscript Submitted by P. Steven Dale

in Partial Fulfillment of the Requirements for the Degree

Master of Science in Biomathematics

August 1980 
Each person whose signature appears below certifies that this manuscript In his opinion is adequate, in scope and quality, in lieu of a thesis for the degree Master of Science.
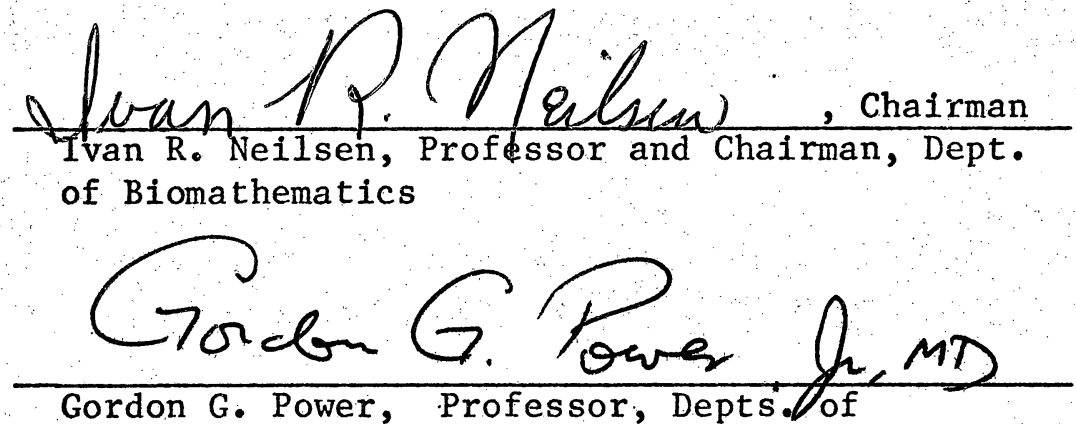

Physiology and Obstetrics and Gynecology

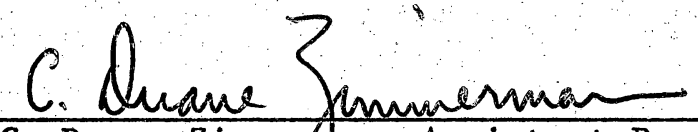

C. Duane Zimmeroman, Assistant Professor, Dept. of Biomathematics
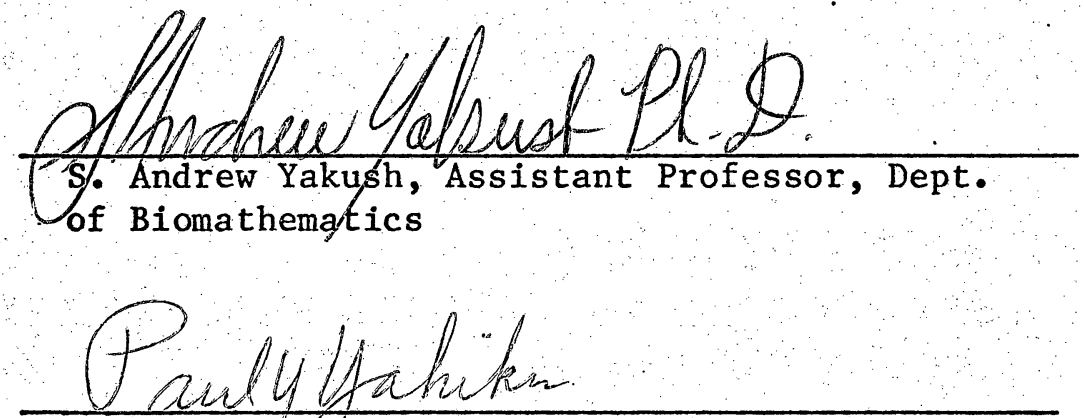

Paul Y. Yajikiku, Associate Professor, Depts. of Biostatistics and Epidemiology 
We wish to thank Sylvia Hixson, Diane McClure, Dr. Dwight Smith, and Debbie Waters for painstaking technical assistance in these experiments. This study was supported in part by U.S. Public Health Service grant HL 15655. The Scientific Computation Facility of Loma Linda University, supported in part by U.S. Public Health Service grant RR 00276, provided computation aid. 
The distribution of maternal and fetal blood flow is an important determinant of the exchange of oxygen, carbon dioxide and water in the placenta. It has been suggested that unevenness in the distribution of the ratio of maternal to fetal flow may be responsible for much of the oxygen tension gradient between the umbilical vein and the uterine vein (12) shown to be virtually non-existent at the end-capillary leve1 (13). This situation would be directly analogous to mismatching of ventilation and blood flow in the lungs, which has been clearly established as a leading cause of impaired respiratory function (21). In addition, unevenness in the distribution of either maternal or fetal flow may be a major factor in promoting water transfer to the fetus (22).

When first measured, the distribution of placental blood flow was reported to be markedly uneven. These early studies reported measurements made in one gram samples of sheep placenta using tagged macroaggregated albumin particles as flow markers (18). Subsequently, flow distribution was reported as more uniform when studied with labeled microspheres, again in relatively large (one to four grams) tissue samples $(19,20)$. The authors of these previous reports have termed them macrodistribution studies, recognizing that the samples taken were very large compared with the dimensions of capillaries and the distances involved in molecular diffusion. It is possible that inhomogeneities exist within tissue samples of this size; thus, an averaging of flows may have obscured the true variation between smaller units.

The present study had four basic purposes: 1) to measure relative maternal and fetal blood flow in small subdivisions of the cotyledons of the sheep placenta, 2) to characterize the spatial pattern of flow distribution within a single cotyledon, 3) to observe the degree of 
correlation between maternal and fetal blood flow, inquiring for evidence of control and interaction, and 4) to assess the consequences of the observed distribution for respiratory gas exchange and water transfer.

It should be emphasized that these experiments deal with the distribution of blood flow within individual cotyledons; absolute flow to the entire placenta or to whole cotyledons was not measured. We worked with the null hypotheses that blood flow within the cotyledon was substantially uniform and that variations in flow among small pieces of the cotyledon were random and not large enough to significantly affect placental function. We hoped to obtain tissue samples small enough for our results to be useful in terms of the theory of placental exchange. METHODS

This study was carried out by injecting large doses of microspheres, labeled with different radionuclides, into the maternal and fetal vessels flowing toward the placenta. The two injections were timed so that the spheres would entrap in placental vessels at about the same time. Since the procedure was executed only once in a given animal, the circulatory derangements which might ensue after extensive capillary plugging could be largely ignored, a point which will be discussed further. The results obtained characterize the distribution of blood flow based on 3,576 samples of placental tissue obtained from seventeen cotyledons taken from six nearterm ewes and their lambs.

Four to five days prior to the experiment the uterus was exposed through a midline abdominal incision under spinal anesthesia $(0.004 \mathrm{mg}$ tetracalne with $0.2 \mathrm{ng}$ epinephrine in $2 \mathrm{ml}$ of $6 \%$ dextrose solution) and barbiturate sedation (pentobarbita1 $7 \mathrm{mg} / \mathrm{kg}, \mathrm{iv}$ ). An injection catheter 
(PE 90) was inserted into the fetal jugular vein under local anesthesia. Its tip was advanced until it lay in the thoracic superior vena cava (SVC), a location from which the injected spheres would pass through both an atrium and a ventricle, to promote mixing, before perfusing the placenta and other fetal organs. The other end of the catheter was exteriorized onto the ewe's back and the animal was allowed to recover.

On the day of the experiment a cardiac catheter was inserted into the ewe's right carotid artery under local anesthesia ( $1 \%$ xylocaine infiltration). Its tip was advanced into the left ventricle (in one instance left atrium) while we monitored its location by pressure tracing. Then with the ewe standing quietly, about fifty million radioactively labeled $\left({ }^{46} \mathrm{Sc},{ }^{57} \mathrm{Co}\right.$ or ${ }^{113} \mathrm{Sn}-3 \mathrm{M}$ or New England Nuclear) microspheres of diameter $14 \pm 1$ (S.D.) $\mu \mathrm{m}$ in a $10 \mathrm{ml}$ suspension containing $0.05 \%$ polyoxyethylene 80 sorbitan monooleate (Tween 80 ) were injected manually over a time interval of about two seconds. Approximately five seconds thereafter, about fifteen million microspheres $\left({ }^{46} \mathrm{Sc},{ }^{85} \mathrm{Sr},{ }^{103} \mathrm{Ru}\right.$ or $\left.{ }^{125} \mathrm{I}\right)$, also of diameter $14 \pm 1 \mu \mathrm{m}$ in a $3 \mathrm{ml}$ suspension were injected into the fetal sVC. This procedure was carried out in four animals. In addition, two animals were each injected with four different radionuclides, the maternal and fetal injections each consisting of a mixture of approximately equal numbers of spheres with two different labels. In all cases the suspension was placed in an ultrasonic bath for ten to thirty minutes prior to the injection, a procedure we have found to be reliable in reducing the number of spheres forming aggregates to about one percent of the total. Since we were concerned solely with the relative distribution of blood flow within the cotyledons, the exact numbers of microspheres and absolute 
blood flows were not determined. The time delay of five seconds was intended to allow both sets of spheres to arrive at the placenta simultaneously (17).

Three minutes after the injections the ewe and the fetus were sacrificed with an overdose of barbiturate; the uterus and placenta were then removed. Three widely separated cotyledons were selected, removed, freed from overlying membranes, and frozen. The cotyledons were diced into cubes about 2 to $3 \mathrm{~mm}$ on edge while kept frozen on an aluminum block partially immersed in dry ice and acetone. The cubes were placed on tared paper and weighed to the nearest $0.1 \mathrm{mg}$ as quickly as possible to minimize errors due to water 1oss. Each tissue sample was then wrapped in its weighing paper and placed in the bottom of a counting vial which was labeled with the sample's $x-y-z$ coordinates for later threedimensional reconstruction. Gamma activity of each piece was counted with a well type counter (Nuclear Chicago or Packard) for two five-minute intervals. Corrections were made for background and overlap and comparisons made with standards containing known numbers of microspheres to determine the number of spheres present in each sample.

As an index of blood flow, the relative activity of each sample was computed. Relative activity is defined as:

$$
\frac{\text { no. spheres in sample / no. spheres in cotyledon }}{\text { weight of sample / weight of cotyledon }}
$$

Thus if $1 \%$ of the spheres were contained in a sample making up $1 \%$ of the weight of the cotyledon, the relative activity of that sample would be unity, a value which if measured everywhere would indicate a homogeneous cotyledon. Similarly, the mean relative activity for an entire cotyledon 
must always be equal to one. Measures of the relation between maternal. and fetal flow in the same sample were also computed by dividing the maternal relative activity by the fetal relative activity (maternal/fetal ratio) and by subtracting the fetal relative activity from the maternal relative activity (maternal-fetal difference).

Finally, in an attempt to determine the degree of aggregation of the spheres within the blood vessels of the cotyledons, we used two additional animals. About fifty million non-radioactive microspheres were injected into the maternal circulation of one and about fifteen million nonradioactive spheres were injected into the fetal circulation of the other. Small samples were taken from three cotyledons of each placenta. Five sections, $10 \mu \mathrm{m}$ thick and separated by a thickness of 50 to $100 \mu \mathrm{m}$, were taken from each sample, stained and examined by light microscopy. RESULTS

Table 1 lists the cotyledon and tissue sample weights, fetal blood gas values at the time of study, and average numbers of microspheres per sample for the individual experiments. The average cotyledon weighed $5.8 \pm 3.1$ (S.D.) grams. It was cut into an average of $210 \pm 120$ pieces weighing $31 . \pm 11$. milligrams each. The average tissue sample contained $470 \pm 290$ maternal spheres and $690 \pm 1050$ fetal spheres. Theoretically these numbers of spheres are sufficient to estimate blood flow with a precision of $10 \%$ at least $95 \%$ of the time (2).

Frequency distribution of maternal and fetal flow. Considerable unevenness was detected in both maternal and fetal blood flow within the cotyledons. Figure 1 shows the observed frequency distribution of maternal and fetal flow, expressed as relative activity. The height of 
each bar represents the fraction by weight. of the cotyledon included in each relative activity interval. These histograms are composite results obtained by averaging similar histograms for the individual cotyledons. Mean relative activity was 1.0 (by definition); both maternal and fetal relative activities had variances of 0.19 and standard deviations of 0.44. Assuming a sample size of 200 , the Kolmogorov-Smirnov goodness of fit test (15) showed neither distribution to be significantly different from a normal distribution ( $p>20)$. The corresponding normal curves are also plotted in Figure 1.

Relation between maternal and fetal flow. Of the various possible measures of the relation between maternal and fetal flow in a particular sample, the maternal/fetal flow ratio is probably most meaningful physiologically. The observed frequency distribution of this ratio, shown in Figure 2, displayed a moderate degree of variability. The ratio was less than 0.5 in $9 \%$ of the cotyledon, between 0.5 and 1.5 in $70 \%$, and greater than 1.5 in $21 \%$. The consequences of the unevenness in this distribution with respect to oxygen exchange will be discussed later.

From the standpoint of theoretical statistics, it is more convenient to express the relation between maternal and fetal flow in terms of the arithmetic difference between them. A composite histogram of the observed distribution of the maternal-fetal difference is shown in Figure 3. The mean was 0.0 , the variance was 0.15 , and the standard deviation was 0.39 ; according to the Kolmogorov-Smirnov test, the distribution was not significantly different from normal $(\mathrm{p}>.20)$. The corresponding normal distribution is plotted in Figure 3 as a solid curve.

Given the experimental distribution of maternal and fetal flow, statis- 
tical theory predicts that the difference between them should be normally distributed with a mean equal to the difference between the two individual means $(1.0-1.0=0.0)$ and a variance equal to the sum of the two individual variances $(0.19+0.19=0.38)$, provided that the two flows are independent (8). This theoretically predicted normal distribution is plotted in Figure 3 as a dashed curve. The experimental distribution is noticeably less variable, suggesting a correlation between maternal and fetal flow. This difference is significant $(p<.05)$ by the KolmogorovSmirnov test.

The correlation between maternal and fetal flow can also be observed by plotting the fetal relative activity as a function of the maternal relative activity for each sample in one cotyledon. Figure 4 contains such a plot for experiment 4, cotyledon 1. In this case the correlation coefficient was 0.58 . Table 2 lists the correlation coefficients for all cotyledons. The average correlation was 0.57 , indicating a significant relationship $(\mathrm{p}<.001)$ given a sample size of 200 .

Spatial distribution of flow. The $x-y-z$ coordinates of the various tissue samples enabled us to look at the spatial distribution of blood flow within the cotyledons. This examination revealed what appeared to be a tendency for both maternal and fetal flow to be lower in the peripheral tissue (near the surface of the cotyledon) and in the central tissue (farthest from the surface) than in the tissue intermediate between the surface and the center.

We found it difficult to express this spatial distribtuion quantitatively, but we were able to visualize it more clearly by applying image processing techniques to the data gathered from the largest cotyledon 
(experiment 2, cotyledon 1). Even with 51.1 samples we expected only marginal results. The statistical distribution of maternal and fetal flow and their ratio, and the maternal-fetal correlation coefficient of 0.55 were all quite similar in this cotyledon to the composite results for all cotyledons. This suggests, but does not prove, that the spatial distributions seen in this case are typical.

Figure 5 contains a series of images representing the patterns of maternal and fetal blood flow in sequential cross-sections of this cotyledon. The color spectrum from red to violet represents high to low relative activities, respectively. Figure 6 depicts the locations of the various cross-sections with respect to the intact cotyledon. Each image in Figure 5 was obtained by first representing the flow, in each tissue sample as a $4 \times 4$ array. Initially, each element of the array was set equal to the relative activity of the sample. For each cross-section all of these arrays were then placed into a larger (128 x 128) array with a value of zero for the background. The two-dimensional Fourier transform was then taken of each of these arrays and a second-order Butterworth low-pass filter with a cutoff frequency of 0.1 was applied. The inverse Fourier transform was taken to obtain the final images (4).

Aggregation of microspheres. In order to quantitatively define the degree of aggregation of microspheres as observed by microscopy, we arbitrarily designated two spheres as forming an aggregate if their centers were seen to be separated by less than $50 \mathrm{~m}$. In the sections containing only maternal spheres a total of 386 microspheres were visual1zed. Sixteen of the spheres were grouped in pairs ( $4 \%$ of the total) and six were found in aggregates of three ( $2 \%$ of the total); no aggregates 
of four or more spheres were found, thus a total of $6 \%$ of the maternal spheres were seen in aggregates. A total of 566 fetal spheres were counted. Sixty of these (11\%) were grouped in pairs and six (1\%) were grouped in threes. Again no aggregates of four or more were detected; a total of $12 \%$ of the fetal spheres were seen in aggregates. Figure 7 is a micrograph of one sample taken from a cotyledon which received microspheres via the fetal circulation. DISCUSSION

These studies are subject to several criticisms which we feel are important enough to define and discuss in some detail.

Statistical nature of the method. When considering the distribution of blood flow as presented in Figure 1, the question arises as to what portion of the observed variability might be explained on the basis of purely statistical effects. Theoretically, if $\mathrm{n}$ microspheres enter a cotyledon and each has probability, p, of arriving at a particular location, the number of spheres actually reaching that location would be a binomial variable with mean, $n p$, and variance, $n p(1-p)$. For the values of $n$ and p relevant to these experiments a binomial variable may be very closely approximated by a normal variable with the same mean and variance (8). In an effort to measure this strictly statistical variability, we injected microspheres labeled with two different radionuclides into the same vesse1. If we let $\mathrm{n}_{1}$ and $\mathrm{n}_{2}$ represent the numbers of spheres of the two nuclides entering a cotyledon and if we let $p$ represent the probability that any particular sphere will reach a specified location within the cotyledon, then the difference between the numbers of spheres of the two nuclides reaching that location should be approximately normally distri- 
buted with mean, $\left(n_{1}-n_{2}\right) p$, and variance $\left(n_{1}+n_{2}\right) p(1-p)$. When expressed in terms of relative activity, the theoretical mean becomes zero and the variance becomes $\left(n_{1}+n_{2}\right)(1-p) /\left(n_{1} n_{2} p\right)$. In six cotyledons we measured $n_{1}$ and $n_{2}$ and assumed $p$ to be equal to the reciprocal of the number of tissue samples. Of the twelve distributions (six maternal and six fetal) obtained experimentally, only three were different from theory $(\mathrm{p}<.05)$ by the Kolmogorov-Smirnov test, and six agreed remarkably well $(p>.20)$. Figure 8 shows the maternal and fetal distributions which were least consistent with theory. The theoretical distributions are plotted as solid curves.

Based on these results we concluded that the variance computed from theory could be used as a relatively reliable predictor of the purely statistical contribution to the variability of maternal and fetal flow in any cotyledon. These theoretical variances were calculated from numbers of maternal and fetal spheres and numbers of tissue samples and expressed in terms of relative activity. The theoretical maternal variance averaged $0.004(2.1 \%$ of the observed total variance of 0.19$)$ with a worst case of 0.014 ( $7.5 \%$ of the observed total). The theoretical fetal variance averaged $0.005(2.6 \%$ of the experimental variance of 0.19$)$ with a worst case of 0.020 ( $10.5 \%$ of the experimental value). The theoretical variance of the maternal-fetal flow difference averaged 0.009 (6.0\% of the observed variance of 0.15 ) with a worst case of 0.023 (15.3\% of the observed variance). Thus, we estimate that our experimental distributions of maternal and fetal blood flow (Figure 1) probably overestimate flow variability by about two to three percent and that the experimental distribution of the maternal-fetal flow difference (Figure 3) may overestimate 
1ts variability by about six percent.

It should be noted that counting error and variation in the radioactivity of individual microspheres would also contribute to the observed variability of flow measurements. The apparent accuracy of the statistical predictions of the distribution of the difference between relative activities measured using two different nuclides indicates that these errors are probably negligible; in our experience, the combined effects of both errors contribute variability that is an order of magnitude smaller than contributed by the binomial statistics discussed above.

Hemodynamic effects of the method. Another question which might be raised involves the effects of possible circulatory derangements, caused by the injections of microspheres, on the results of these experiments. As mentioned earlier the spheres were in jected rapidly and carried in the arterial stream as a bolus so as to arrive and lodge in the placenta separated by no more than a few seconds. Any circulatory derangement sufficient to invalidate the experiments would have had to occur within this time interval. The sudden delivery of microspheres is evidence against any alterations in flow patterns caused by chemical or neural mechanisms and appears to limit the extent of even purely mechanical effects.

In addition, our measurements gave no evidence of significant hemodynamic alterations. Maternal blood pressure was monitored during the experiments. The general tendency was for blood pressure to fall slightly following the injections of microspheres. The largest effect seen was a drop of $10 \mathrm{~mm} \mathrm{Hg}$; in most cases the maternal blood pressure fell between 0 and $5 \mathrm{~mm} \mathrm{Hg.} \mathrm{Thus} \mathrm{maternal} \mathrm{uterine} \mathrm{flow} \mathrm{is} \mathrm{not} \mathrm{likely} \mathrm{to} \mathrm{have} \mathrm{fallen}$ 
materially nor vessels to have collapsed subsequent to the injections. Fetal blood pressure was recorded only during the experiments using unlabeled spheres. No changes were detected when spheres were injected Into the maternal circulation, and when spheres were injected into the fetal circulation blood pressure rose about $3 \mathrm{~mm} \mathrm{Hg}$. There were no observable changes in fetal heart rate, arterial $\mathrm{PO}_{2}, \mathrm{PCO}_{2}, \mathrm{pH}$ or hematocrit. In other studies in fetal sheep, injections of one million or more microspheres $15 \mu \mathrm{m}$ in diameter have been repeated on five occasions without significant effects (6). In dogs as many as 21 million spheres of 7 to 10 $\mu \mathrm{m}$ diameter have been injected without apparent adverse effects (3). Other possible systematic errors. Another problem which merits consideration is the possible formation of chains of microspheres within the blood vessels (5). As mentioned previously, we were unable to find any aggregates of more than three microspheres in the tissue sections we examined microscopically. Given the numbers of spheres present in the tissue samples and the fact that roughly $90 \%$ of the spheres were trapped individually, we expect that the variability introduced into our measurements by the aggregation of spheres was minute.

In general, the mechanisms which might be invoked to question the validity of these flow measurements would produce varying results depending on the concentration of microspheres. In Figure 9 are plotted the observed variances of maternal and fetal flow for each cotyledon as a function of the number of maternal or fetal spheres per gram in that cotyledon. No significant linear or quadratic relationship was found between the concentration of microspheres and the maternal or fetal variance. This result tends to minimize the probability that systematic errors of the method 
significantly influenced our findings.

Physiological implications. These experiments do not clearly indicate the source of the variability of blood flow or the mechanisms involved in the correlation between maternal and fetal flow. Some of the observed flow unevenness is certainly anatomical, reflecting variations in capillary volume per unit tissue mass. It is possible that a large proportion of the experimental variance is due to this distribution of capillary volume. Another potential source of variability is the distribution of blood flow per unit capillary volume, reflecting variations in the velocity of blood flow. Inhomogeneities of capillary flow velocity in other microvascular beds have been well documented (9).

If variations in placental capillary flow velocities contribute significantly to the experimentally measured unevenness of maternal or fetal flow, placental water exchange would be affected. We have used the mathematical model of Wilbur, et. al. (22) to predict placental water flux for different values of the variance of maternal and fetal flow velocity. A bivariate normal distribution (23) of maternal and fetal flow was assumed with equal variances and a correlation of 0.57 . The resultant curve is plotted in Figure 10. If we speculate that one-half of the experimental variance $(0.19 / 2=0.095)$ were due to flow velocity differences, it can be seen from Figure 10 that the contribution to placental water flux would be about $0.05 \mathrm{ml} / \mathrm{min}$. Since the normal net water flux toward the fetus is only about $0.015 \mathrm{ml} / \mathrm{min}$, the possibility is ralsed that changes in flow variability might bring about very large shifts in water transfer, conceivably acting as a high-gain control mechanism. 
Regardless of its source, unevenness in the distribution of the ratio of maternal to fetal blood flow would affect placental oxygen exchange. Calculations based on the mathematical model of Hill, et. al. $(7,11)$ were used to ascertain the contribution to oxygen exchange by each compartment of Figure 2. Following the method detailed by Longo and Power (12) we arrived at a predicted uterine vein-umbilical vein oxygen tension difference of about $6 \mathrm{~mm} \mathrm{Hg}$; this explains roughly $50 \%$ of the gradient commonly observed. These calculations ignore potential contributions to the venous $\mathrm{PO}_{2}$ gradient due to arteriovenous shunts of sufficient size to prevent the entrapment of $14 \mu \mathrm{m}$ microspheres, significant flow variations between capillaries in the same tissue sample, or variations between cotyledons.

Concepts of the placental exchange unit. The tissue samples in this study were small cubes' weighing about $30 \mathrm{mg}$. The possibility of variations within a single sample suggests the question of how these cubes compare in size to the dimensions over which placental exchange is controlled. We shall discuss three main concepts of the placental exchange unit, comparing their dimensions and implications for the transfer of gases and nutrients. These are diagrammed in Figure 11.

The classic model for tissue oxygen exchange has been the Krogh cylinder, in which a capillary is considered to provide $\mathrm{O}_{2}$ to a surrounding. sleeve of tissue. This is usually modified for the sheep placenta by considering maternal and fetal capillaries as two parallel pipes (Panel A, Figure 11) with diffusion proceeding only at right angles to the length of the capillaries ( $1 . e .$, longitudinal diffusion is ignored) and in which oxygen is supplied only to Immediately adiacent tissues and capillaries 
(diffusion between more widely separated cylinders is ignored). Thus the size of the unit is related to the distance between capillaries, which is readily calculated. From the geometry of concentric cylinders the fractional volume of the capillaries is given by $v_{c} / v_{t}=R_{c}{ }^{2} /\left(R_{t}{ }^{2}-\right.$ $R_{c}{ }^{2}$ ) where $V_{c}$ and $V_{t}$ are the volumes of the capillaries and the tissue cylinders, and $R_{c}$ and $R_{t}$ their radii, respectively. Reasonable estimates for placental capillary volume range from $10 \mathrm{ml}$ (14) to $40 \mathrm{ml}$ (1) in sheep placentas weighing about $500 \mathrm{~g}$. The radius of the capillaries $\left(R_{c}\right)$ may be estimated as $4 \mu \mathrm{m}$. Substituting into the expression above gives an intercapillary spacing $\left(2 R_{t}\right)$ of 29 to $57 \mu \mathrm{m}$. If one assumes an average capillary length of $800 \mu \mathrm{m}$ it is found that the anatomic placental exchange unit weighs only $5.3 \times 10^{-4}$ to $2.0 \times 10^{-3} \mathrm{mg}$. The $30 \mathrm{mg}$ tissue samples which impressed the authors as tiny would have each contained 15,000 to 57,000 such units.

Since the simple anatomic model described above cannot do iustice to the complicated interdigitation of vessels in the placenta, we next suggest the concept of the functional exchange unit. In this model the size of the placental exchange unit is determined by dimensions that will maintain a specified oxygen level regardless of anatomy.

We define the functional unit as the maximally sized cylinder of tissue through which as oxygen molecule can diffuse, under existing partial pressure gradients, in sufficient quantity to explain measured transfer rates. We further simplify the definition by considering maternal blood as a source of $\mathrm{O}_{2}$, located along the axis of a cylinder and fetal blood as homogeneously distributed in a surrounding outer sleeve of tissue. Oxygen levels will vary throughout the tissue cylinder depending 
on: 1) distance along the capillary and 2.) radial distance from the capillary, as pictured in Panel B, Figure 11.

Based on measured oxygen tension in the uterine and umbilical veins, we estimate mean tissue $\mathrm{O}_{2}$ tension within such a cylinder to be about 32 $\mathrm{mm} \mathrm{Hg}$. We estimate mean maternal capillary $\mathrm{PO}_{2}$ to be between 40 and 50 $\mathrm{mm} \mathrm{Hg}$, giving a maximum mean capillary-tissue difference of $50-32=18$ $\mathrm{mm} \mathrm{Hg}$. From an integrated form of Krogh's equation, presented in convenient form with aids for calculation by Kety (10), the radius of the tissue cylinder is calculated to be about $40 \mu \mathrm{m}$, and the size of the functional exchange unit, assuming a length of $800 \mu \mathrm{m}$, is found to be $4.0 \times 10^{-3} \mathrm{mg}$. Each tissue sample we studied would have contained 7500 such units.

We finally consider the definition of the exchange, unit as a region containing daughter branches of a vessel whose resistance; size and response to control stimuli may vary. As shown in Panel C, Figure 11, blood enters through a large inflowing branch which undergoes successive subdivisions. The blood is then considered to pass through vessels that impose a significant resistance to flow. Resistance may vary with location, possibly due to passive anatomical arrangements, or perhaps with time, due to active control mechanisms. The exchange unit is considered to be the capillary bed descended from a single such resistance vessel (circled with a broken line in Panel C, Figure 11).

Clearly these regulatory units are appreciably larger than the anatomic and functional units already described. Furthermore, their boundaries may be blurred when oxygen diffuses between adjacent capillaries that may be fed by different resistance vessels. A clue to the dimensions of possible placental regulatory exchange units was obtained when the 
following computer study was performed.

Computer simulation of various tissue sample sizes. Given the observed unevenness in the distribution of placental blood flow, we approached the question of what we would have observed had we chosen larger or smaller dimensions for our subdivisions of the cotyledons. We were interested in comparing our results with those of other investigators and determining if the unevenness we detected is characteristic of some basic substructure within the cotyledon. In order to answer this question without numerous replications of the experiments, we relied on computer analysis of our original data. We attacked the problem in terms of the correlation in blood flow between samples separated by varying distances.

For each cotyledon all possible rectangular distances between two samples, $\sqrt{\Delta \mathrm{x}^{2}+\Delta \mathrm{y}^{2}+\Delta \mathrm{z}^{2}}$, were determined. The relative activity of each sample was compared to the average relative activity at the specified distance away. For each distance, the maternal and fetal correlation coefficient was calculated within each cotyledon. Results for the different cotyledons were averaged; the composite relationships are plotted in Figure 12.

The flow correlation (both maternal and fetal) between immediately ad jacent samples was highly significant, but the correlation decreased to zero at a separation equal to the dimension of about two samples. This finding is consistent with the spatial organization of flow displayed in Figure 5. Based on these results we considered a hypothetical spherical regulatory unit with a radius equal to the dimension of a single tissue sample. Since the average sample weighed $30 \mathrm{mg}$, this weight would be $30 \mathrm{x}$ $4 \pi / 3=126 \mathrm{mg}$. Whether this value simply reflects an anatomical character- 
istic or is evidence for active regulation remains to be determined. Theoretically, if there were no correlation between adiacent samples, the observed flow variance should be inversely proportional to the size of the samples. As derived above, this should be approximately true for samples larger than about $125 \mathrm{mg}$. This effect is probably sufficient to account for the discrepancy between the present study and the work of Rankin, et. al. $(19,20)$ who obtained variances around one-tenth of our values. The apparent substantial agreement between our present work and the earlier studies of Power, et. al. (18) is probably articfactual since the earlier experiments used much larger tissue samples. The earlier method using macroaggregated albumin particles may have overestimated true flow variability.

It would be tempting to generalize from Figure 12 that had we taken progressively smaller tissue samples we would have found increasing correlation between adjacent samples. If this were true our results would be good estimates (perhaps somewhat too low) of the variability of flow among smaller placental subdivisions. However, such speculation might be subject to huge errors given our lack of information on the distribution of flow within the tissue samples, at the capillary level. SUMMARY

These experiments offer evidence that blood flow is unevenly distributed among $30 \mathrm{mg}$ subdivisions within cotyledons of the sheep placenta. The nonuniformity seems to exhibit spatial organization and should be observable among tissue samples as large as about $125 \mathrm{mg}$. A portion of this unevenness is probably effective as a determinant of placental water exchange. Although a significant correlation exists between maternal 
and fetal flow, there still appears to be enough mismatching to explain a $6 \mathrm{~mm} \mathrm{Hg}$ uterine-umbilical venous $\mathrm{PO}_{2}$ difference. Further investigation is required to determine the mechanisms involved in the correlation between maternal and fetal flow, and the role, if any, of changes in flow variability in the active regulation of water exchange. We conclude that flow inhomogeneity is a major cause of less than ideal placental exchange during normal pregnancy. 
1. BISSONNETTE, J.M. and R.C. FARRELL. Pressure-flow and pressure volume relationships in the fetal placental circulation. J. Appl. Physio1. 35: 355-360, 1973.

2. BUCKBERG, G.D., J.C. LUCK, B.D. PAYNE, J.I.E. HOFFMAN, J.P. ARCHIE, and D.E. FIXLER. Some sources of error in measuring regionaI blood flow with radioactive microspheres. J. Appl. Physiol. $31: 598-604,1971$.

3. FALSETTI, H.L., R.J. CARROLL, and M.L. MARCUS. Temporal heterogeneity of myocardial blood flow in anesthetized dogs. Circulation. $52: 848-853,1975$

4. GONZALEZ, R.C., and P. WINTZ. In: Digital Image Processing. Reading, Mass., Addison-Wesley Publishing Co., 1977, pp. 36-88, 145-148.

5. HARELL, G.S., W.A. DICKHONER, and R.S. BREIMAN. The simultaneous visualization of microspheres and blood flow in the microvascular bed of the hamster cheek pouch. Microvasc. Res. 13: 203-210, 1977.

6. HEYMANN, M.A., B.D. PAYNE, J.I.E. HOFFMAN, and A.M. RUDOLPH. Blood flow measurements with radionuclide-labeled particles. Progress in Cardiovasc. Dis. $20(1): 55-79,1977$.

7. HILL, E.P., G.G. POWER, and L.D. LONGO. A mathematical model of placental $\mathrm{O}_{2}$ transfer with consideration of hemoglobin reaction rates. Am. J. Physiol. 222(3): 721-729, 1972.

8. HOEL, P.G., S.C. PORT, and C.J. STONE. In: Introduction to Probability Theory. Boston, Houghton Mifflin Co., 1971, pp. 51, 75, 149, 185-189. 
9. JOHNSON, P.C., and H. WAYLAND. Regulation of blood flow in single capillaries. Am. J. Physiol. 212(6): 1405-1415, 1967.

10. KETY, S.S.. Determinants of tissue oxygen tension. Fed. Proc. $16: 666-670,1957$.

11. LONGO, L.D., E.P. HILL, and G.G. POWER. Theoretical analysis of factors affecting placental $0_{2}$ transfer. Am. J. Physiol. $222(3): 730-739,1972$.

12. LONGO, L.D. and G.G. POWER. Analyses of $\mathrm{PO}_{2}$ and $\mathrm{PCO}_{2}$ differences between maternal and fetal blood in the placenta. J. Appl. Physiol. 26(1):48-55, 1969.

13. LONGO, L.D., G.G. POWER, and R.E. FORSTER, II. Respiratory function of the placenta as determined with carbon monoxide in sheep and dogs. J. Clin. Invest. 46:812-828, 1967.

14. LONGO, L.D., G.G. POWER, and R.E. FORSTER, II. Placental diffusing capacity for carbon monoxide at varying partial pressures of oxygen. J. App1. Physiol. 26(3): 360-370, 1969.

15. MASSEY, F.J.. The Kolmogorov-Smirnov test for goodness of fit. J. Am. Stat. Assn. 46: 68-78, 1951 .

16. POWER, G.G., E.P. HILL, and L.D. LONGO. Analysis of uneven distribution of diffusing capacity and blood flow in the placenta. Am. J. Physiol. 222(3): 740-746, 1972.

17. POWER, G.G. and L.D. LONGO. Fetal circulation times and their implications for tissue oxygenation. Gynecol. Invest. 6: 342$355,1975$. 
18. POWER, G.G., L.D. LONGO, H.N. WAGNER, JR., D.E. KUHL, and R.E. FORSTER, II. Uneven distribution of maternal and fetal blood flow, as demonstrated using macroaggregates, and its response to hypoxia. J. Clin. Invest. 46: 2053-2063, 1967.

19. RANKIN, J.H.G., G. MESCHIA, E.L. MAKOWSKI, and F.C. BATTAGLIA. Distribution of blood flow in the sheep placenta. Am. J. Physiol. 219: 9-16, 1970.

20. RANKIN, J.H.G., and J.M. SCHNEIDER. Effect of surgical stress on the distribution of placental blood flows. Respiration Physiol. $24: 373-383,1975$

21. WEST, J.B.. In: Ventilation/Blood Flow and Gas Exchange (2nd ed.). Oxford, Blackwe11, 1970.

22. WILBUR, W.J., G.G.POWER, and L.D. LONGO. Water exchange in the placenta: a mathematical model. Am. J. Physiol. 235(3): R181R199, 1978.

23. ZELEN, M., and N.C. SEVERO. "Probability Functions", In: Handbook of Mathematical Functions. M. Abramowitz and I.A. Stegun (eds.), Washington, National Bureau of Standards, 1970. 


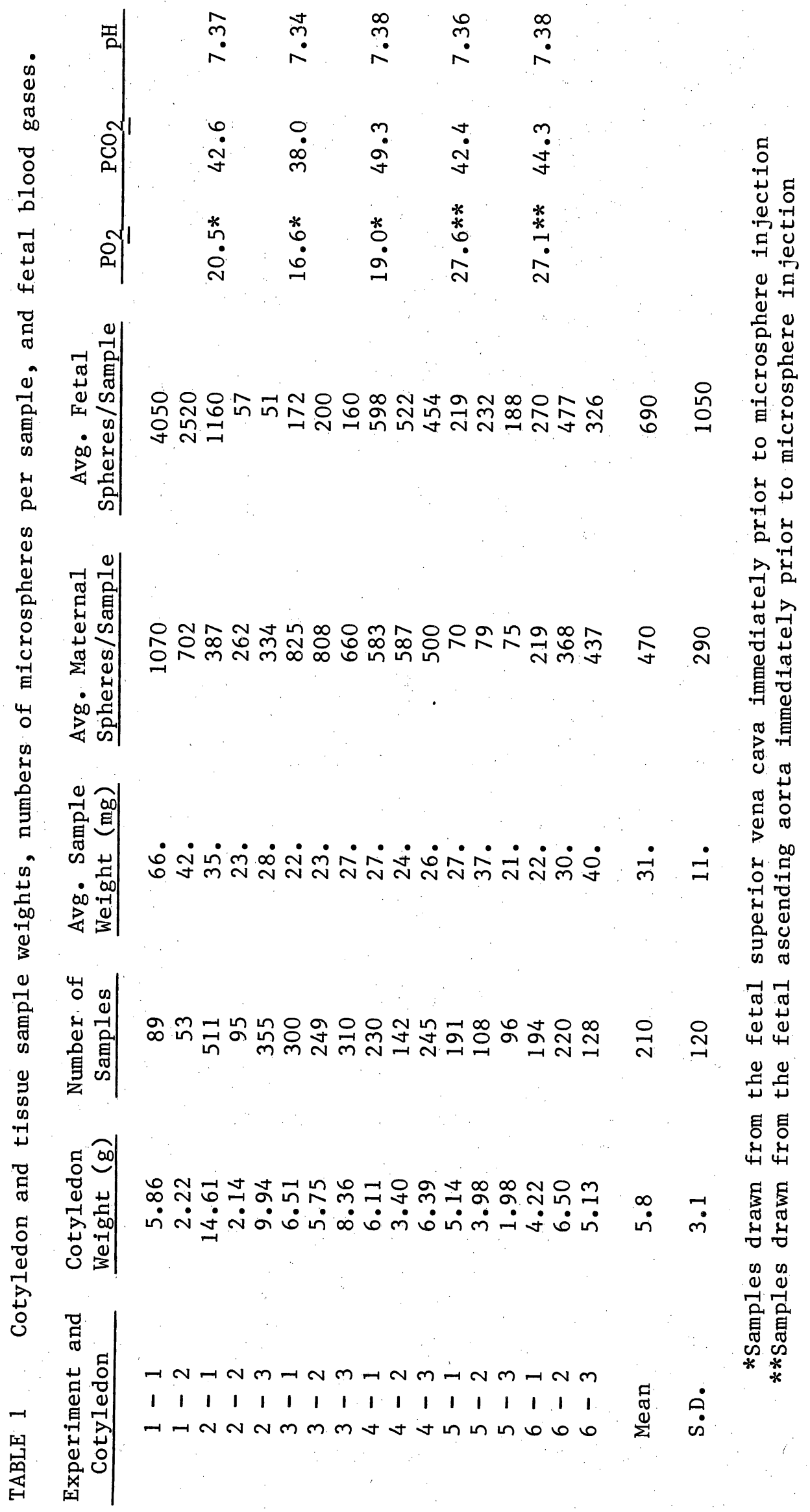


TABLE 2 Correlation between maternal and fetal flow in individual cotyledons

Experiment and Cotyledon

$$
1-2
$$$$
1-3
$$$$
2-1
$$$$
2-2
$$$$
2-3
$$$$
3-1
$$$$
3-2
$$$$
3-3
$$$$
4-1
$$$$
4-2
$$$$
4-3
$$$$
5-1
$$$$
5-2
$$$$
5-3
$$$$
6-1
$$$$
6-2
$$$$
6-3
$$

Mean

\section{Correlation \\ Coefficient}

0.18

$-0.29$

0.55

0.30

0.58

0.60

0.83

0.63

0.58

0.53

0.59

0.80

0.72

0.77

0.60

0.84

0.85

0.57

\section{Significance}

insignificant

$\mathrm{p}<.05$

$p<.001$

$\mathrm{p}<.05$

$\mathrm{p} \ll .001$.

$p<.001$

$\mathrm{p} \ll .001$

$p<.001$

$p \ll .001$

$p<.001$

$p \ll .001$

$\mathrm{p}<0.001$

$p \ll .001$

$p<.001$

$p \ll .001$

$p \ll .001$

$\mathrm{p}<<.001$

p $<.001$ 
LEGENDS FOR FIGURES

Figure 1. Frequency distribution of maternal and fetal blood flow within the average cotyledon. Flow is expressed as relative activity and frequency is expressed in terms of percent by weight of the cotyledon. The error bars indicate standard errors of the means. The standard deviation of both maternal and fetal relative activity was 0.44 ; the corresponding normal curve is shown. The number of samples with maternal or fetal relative activity greater than 2.0 was negligible.

Figure 2. Frequency distribution of the ratio of maternal to fetal blood flow within the average cotyledon. Frequency is expressed in terms of the percent by weight of the cotyledon. The error bars indicate standard errors of the means. The number of samples with maternal/ fetal flow greater than 4.0 was negligible.

Figure 3. Frequency distribution of the difference between maternal and fetal blood flow within the average cotyledon. Flow is expressed as maternal minus fetal relative activity. Frequency is expressed in terms of the percent by weight of the cotyledon. The error bars indicate standard errors of the means. The standard deviation of maternal-fetal relative activity was 0.39 ; the solid curve represents the corresponding normal distribution. The distribution predicted from Figure 1, assuming maternal and fetal flow to be independent, had a standard deviation of 0.62 and is plotted as a dashed curve. 
Figure 4. Fetal vs. maternal blood flow in experiment 4, cotyledon 1. Each point represents one tissue sample from the cotyledon. Flow is expressed as relative activity. The correlation coefficient was $0.58(\mathrm{~N}=230, \mathrm{p} \ll .001)$. A symmetrical regression line is shown.

Figure 5. Spatial distribution of maternal and fetal blood flow in experiment 2, cotyledon 1. Each image represents a cross-section of the cotyledon. The color spectrum from red to violet represents high to low relative activities, respectively. The positions of the different cross-sections with respect to the intact cotyledon are indicated in Figure 6.

Figure 6. Schematic drawing of an intact cotyledon. Each labeled crosssection corresponds to one pair of images in Figure 5.

Figure 7. Micrograph of a tissue sample containing non-radioactive microspheres in only the fetal circulation. Microspheres are indicated by arrows; one aggregated pair of microspheres is seen in this example.

Figure 8. Statistical scatter of the microsphere method. The frequency distribution of the difference between maternal relative activities measured by two different radionuclides (experiment 6 , cotyledon 2) and between fetal relative activities measured by two additional nuclides (experiment 5, cotyledon 1) are shown. According to the Kolmogorov-Smirnov goodness of fit test, these were the maternal and fetal distributions least consistent with theoretical predictions 
based on binomial statistics. The theoretical distributions are plotted as solid curves.

Figure 9. Effects of varying numbers of microspheres. The variance of maternal and fetal relative activity measured in the individual cotyledons is plotted vs. the number of microspheres per gram in the cotyledon. The composite variance (as shown in Figure 1) is indicated by dashed lines. The correlation coefficient for the maternal measurements was 0.25 ; for the fetal measurements it was 0.19. Standard regression techniques detected no significant linear or quadratic relationship.

Figure 10. Theoretical relation between water transfer and flow unevenness. Contribution to placental water flux (toward the fetus) due to blood flow unevenness is plotted vs. flow variance. A bivariate normal distribution was assumed for maternal and fetal flow, with equal variances and a correlation of 0.57 . This figure should be interpreted as predicting changes in water flux produced by changes in the velocity component of flow variance from some hypothetical normal, steady-state value.

Figure 11. Three concepts of the placental exchange unit. 'A' shows an anatomic unit whose size depends on the distance between maternal and fetal capillaries. ' $B$ ' shows a functional unit whose size depends on the maximal dimensions that will maintain a specified exchange rate for $\mathrm{O}_{2}$. ' $\mathrm{C}$ ' shows a regulatory unit consisting of daughter branches from an upstream resistance vessel. 
Figure 12. Correlation between samples vs. distance between samples. Each point (except at zero distance $r=1.0$ by definition) represents the measured flow correlation (maternal or fetal), in the average cotyledon, between tissue samples separated by the given distance. Distance is expressed in arbitrary units corresponding to the dimensions of one tissue sample. The error bars indicate standard errors of the means. 

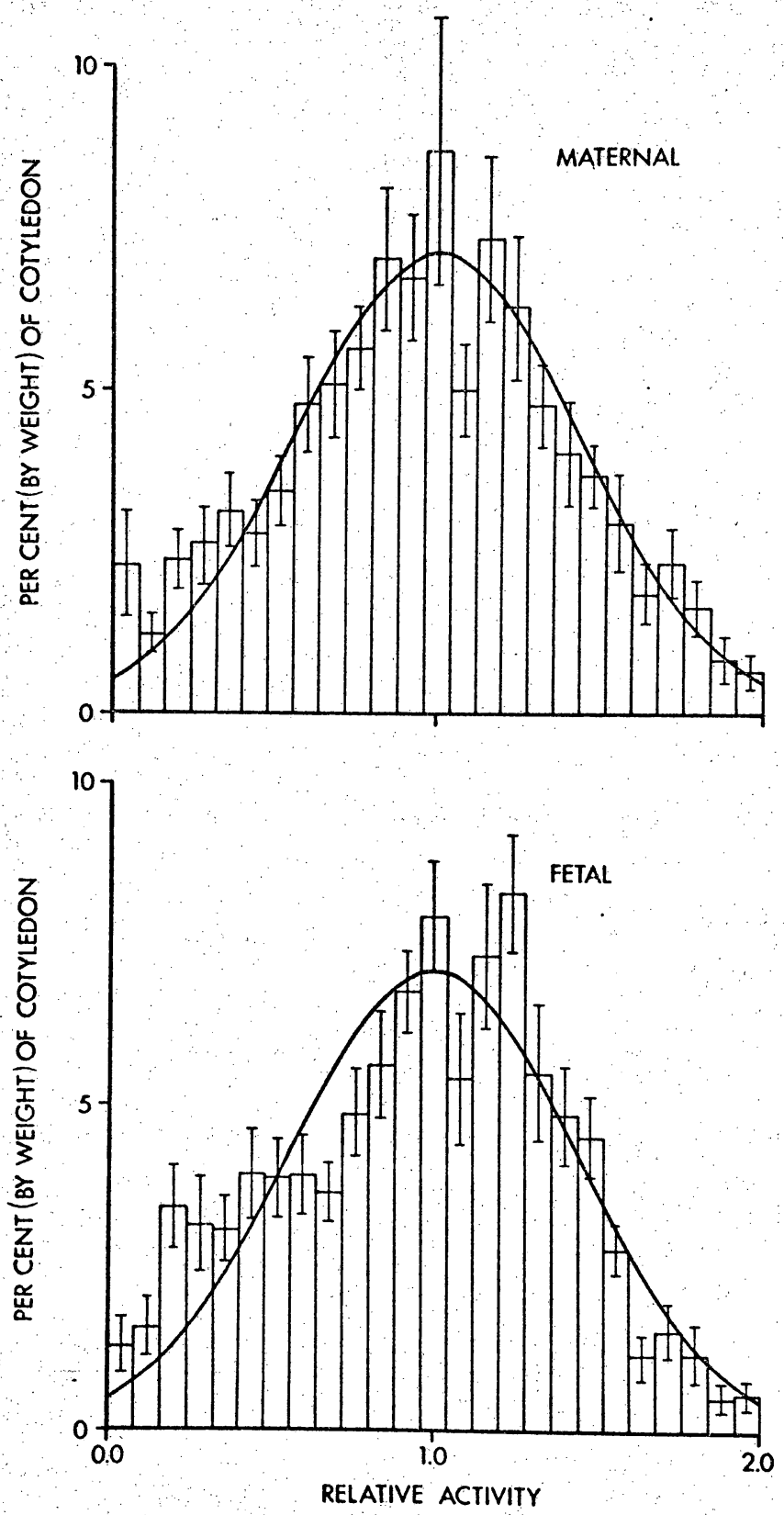

FIGURE 1 


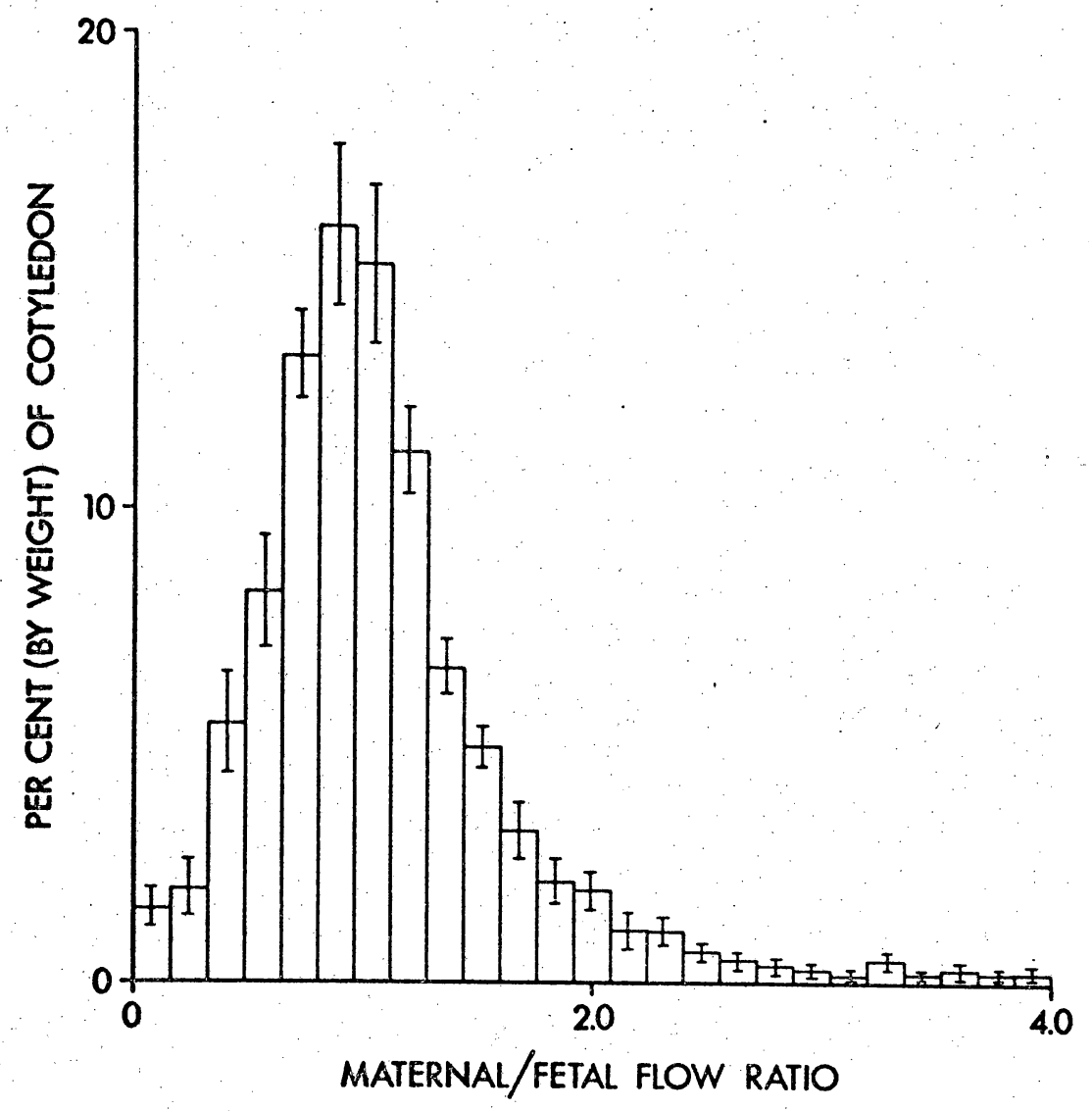

FIGURE 2 


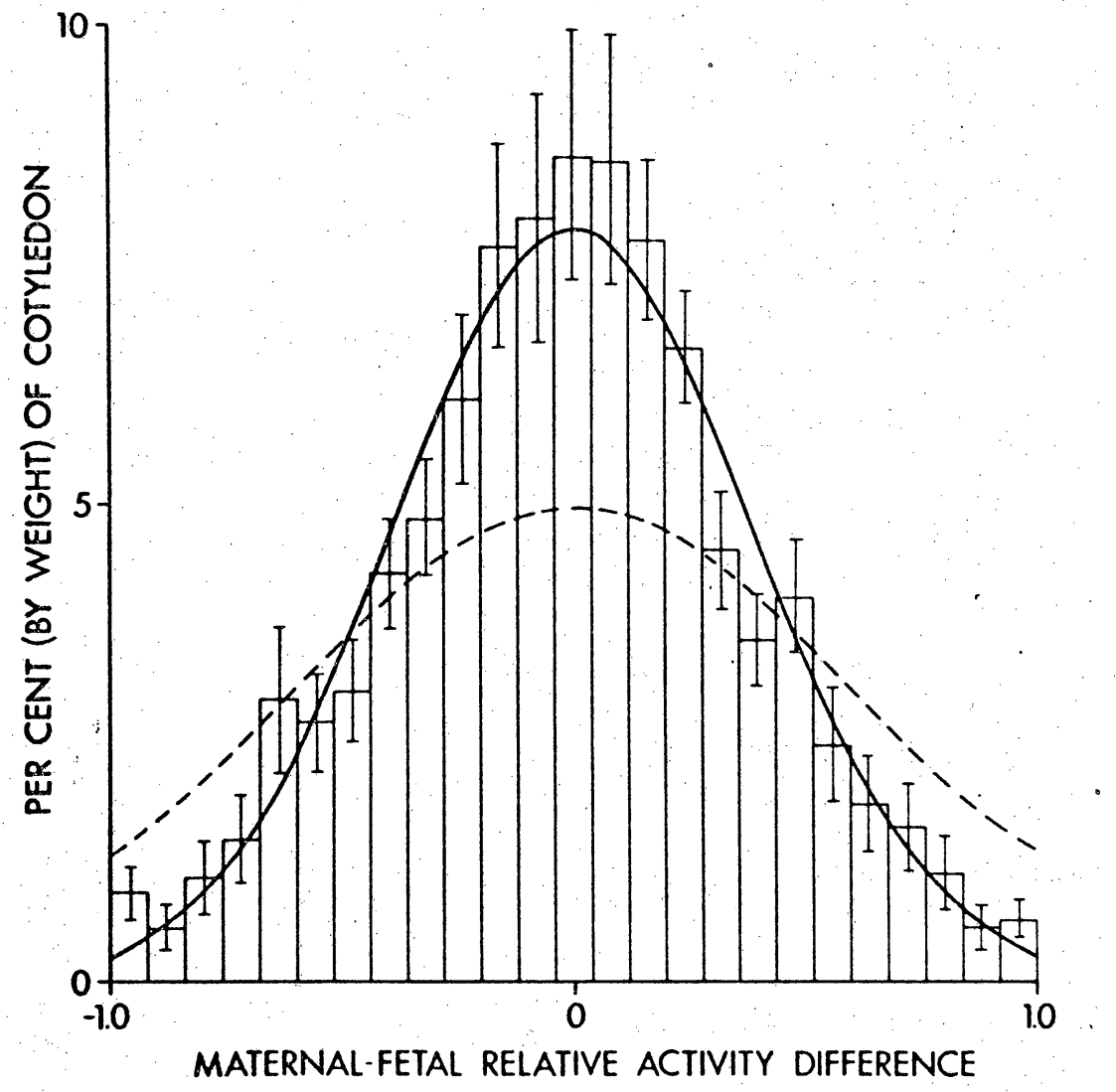

FIGURE 3 


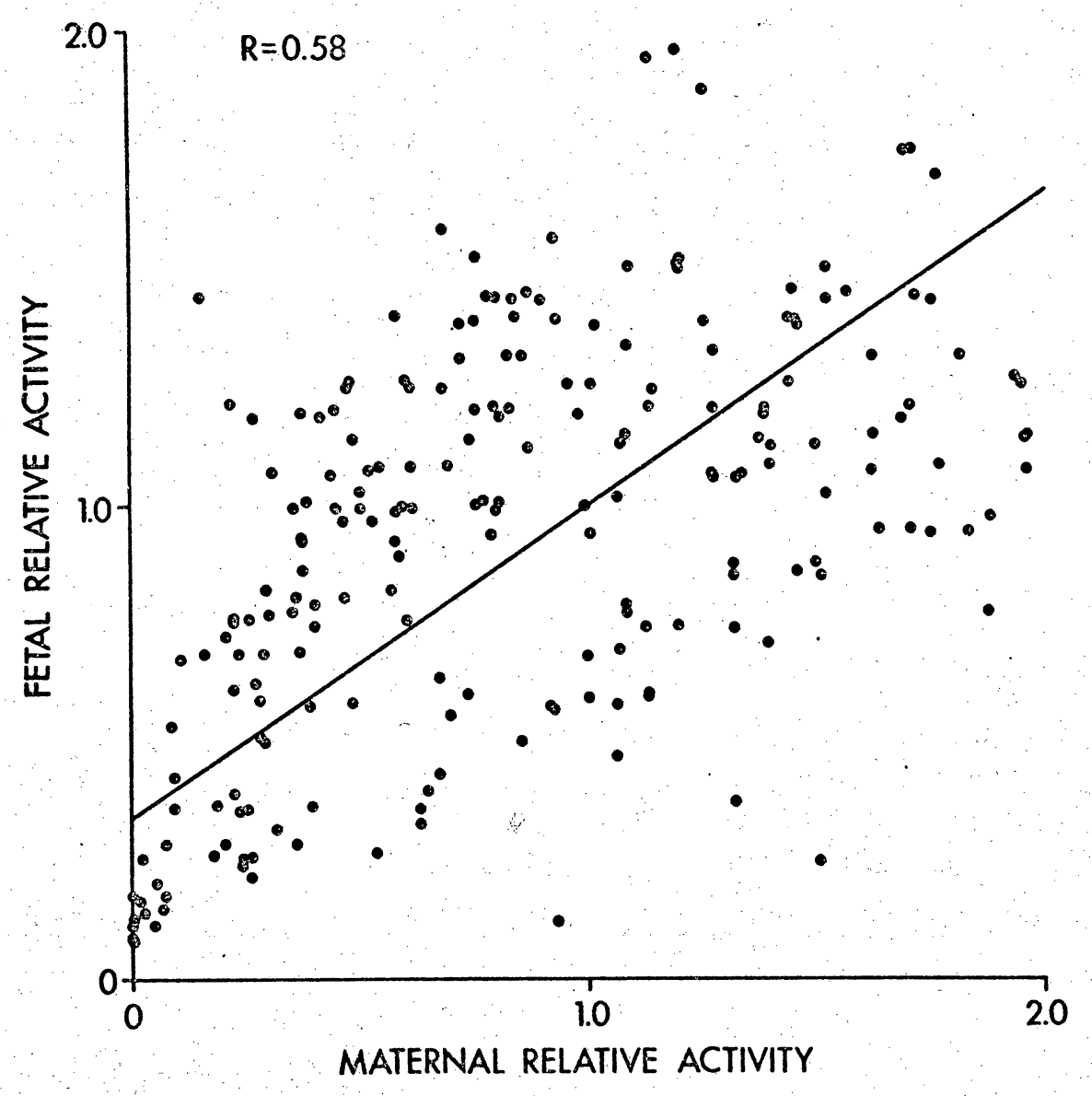

FIGURE 4 


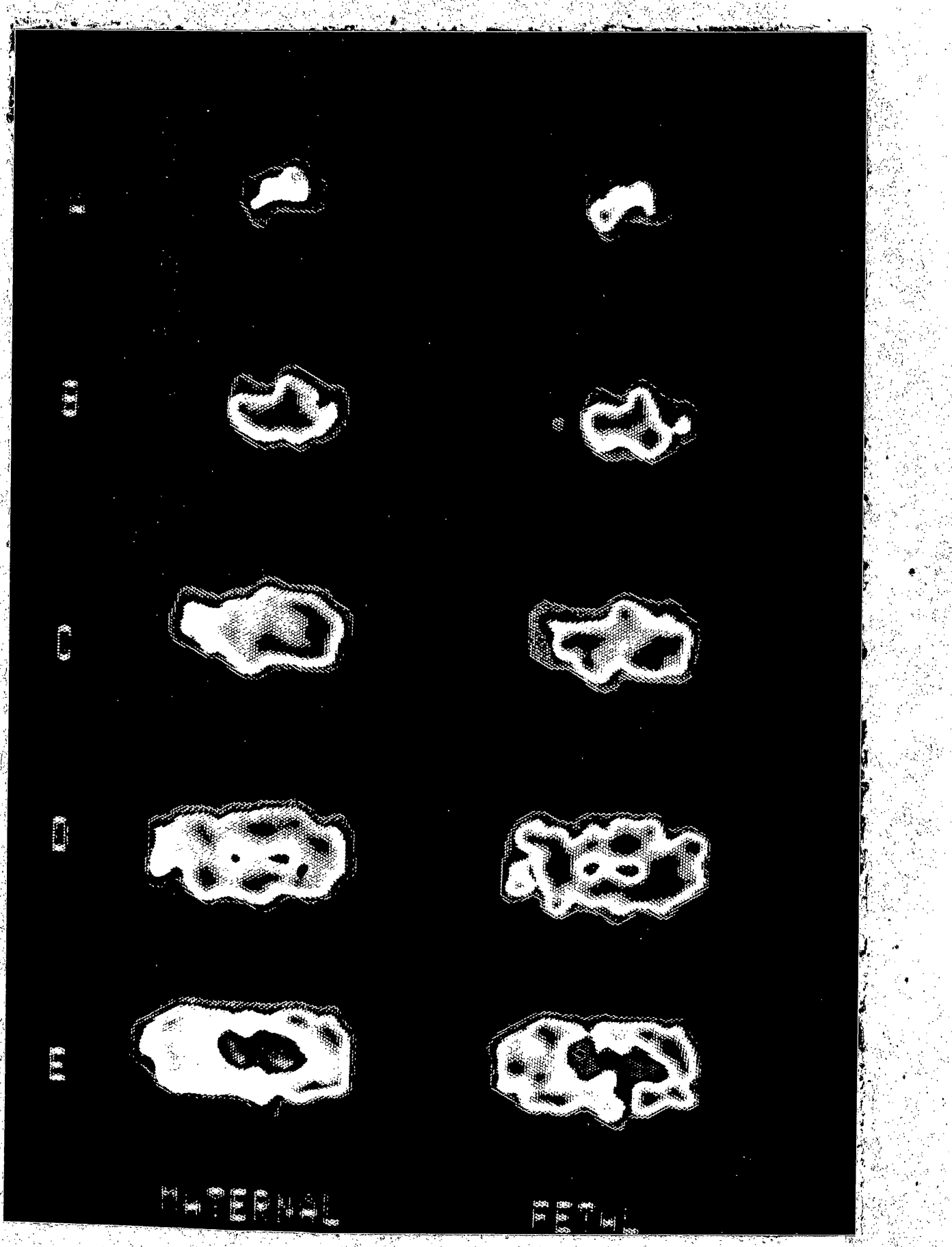

FIGURE 5 
ENDOMETRIAL SURFACE

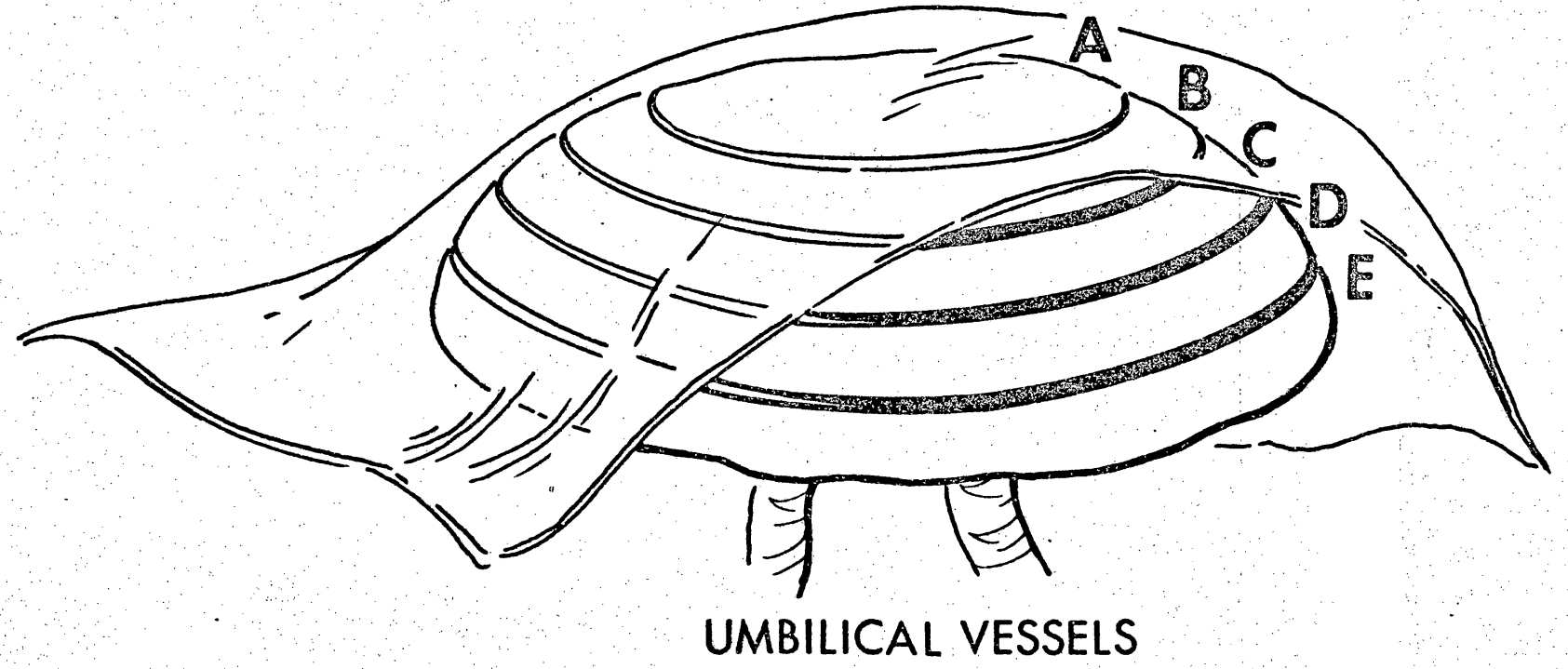

FIGURE 6 

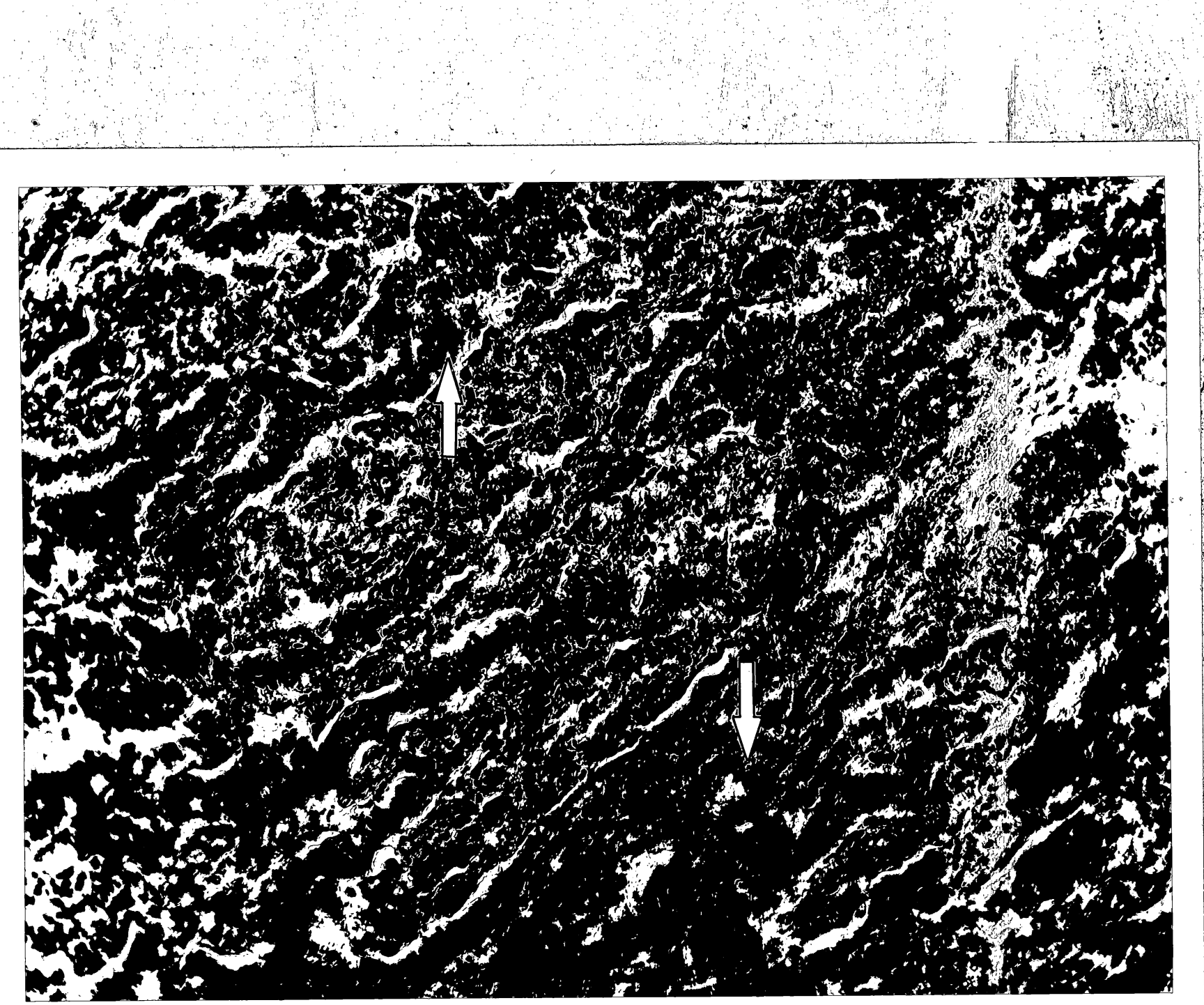

FIGURE 7 

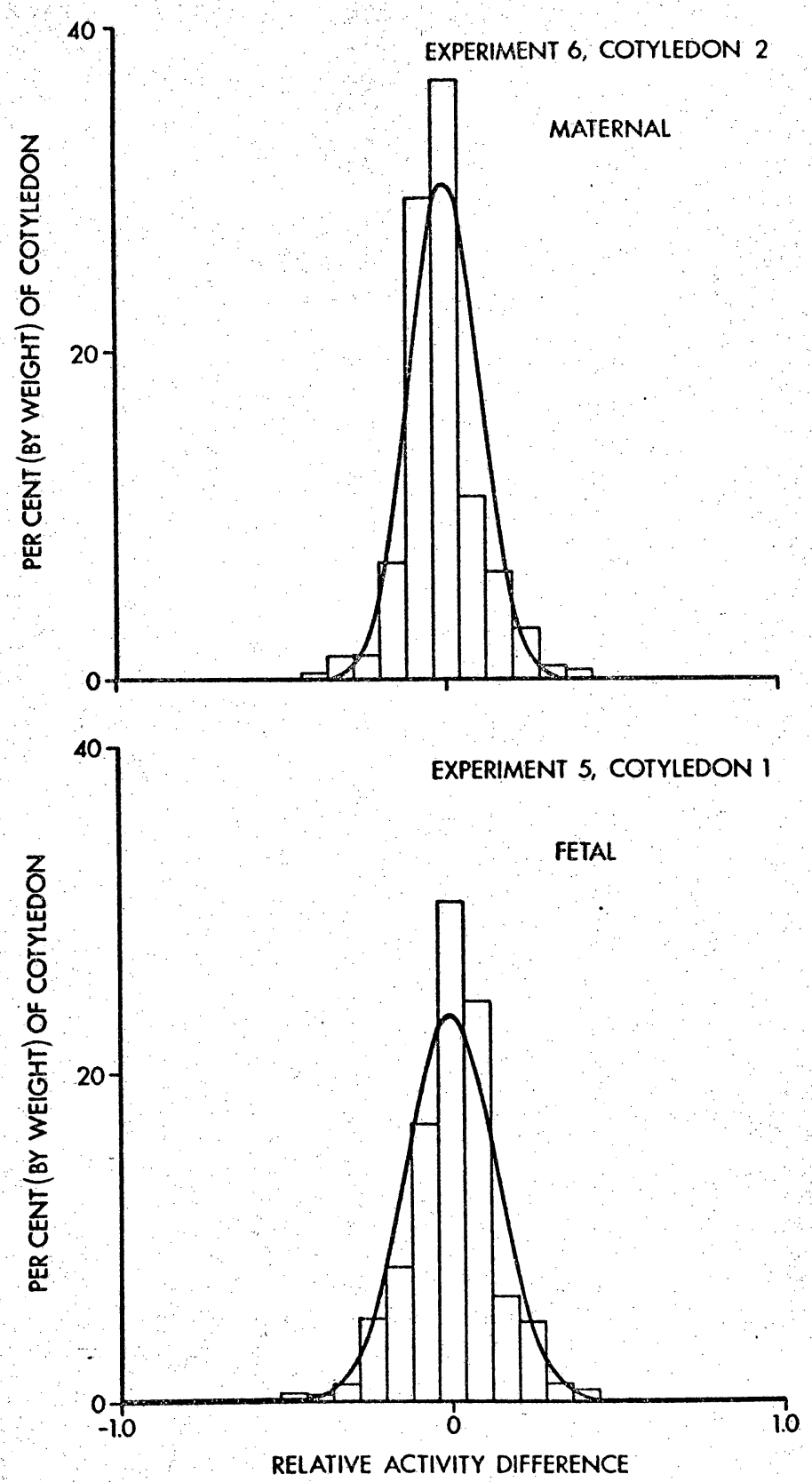

FIGURE 8 

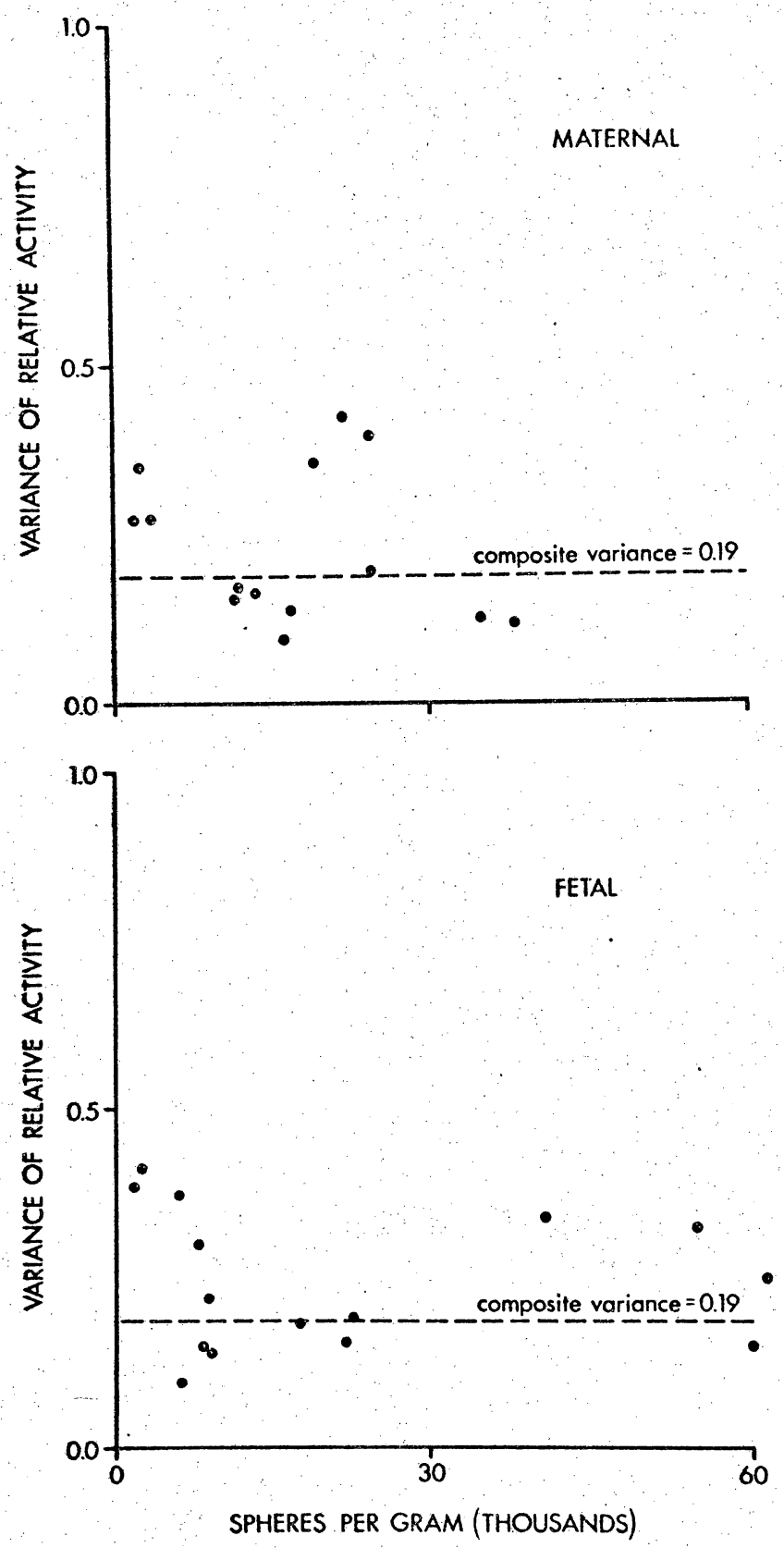

FIGURE 9 
38

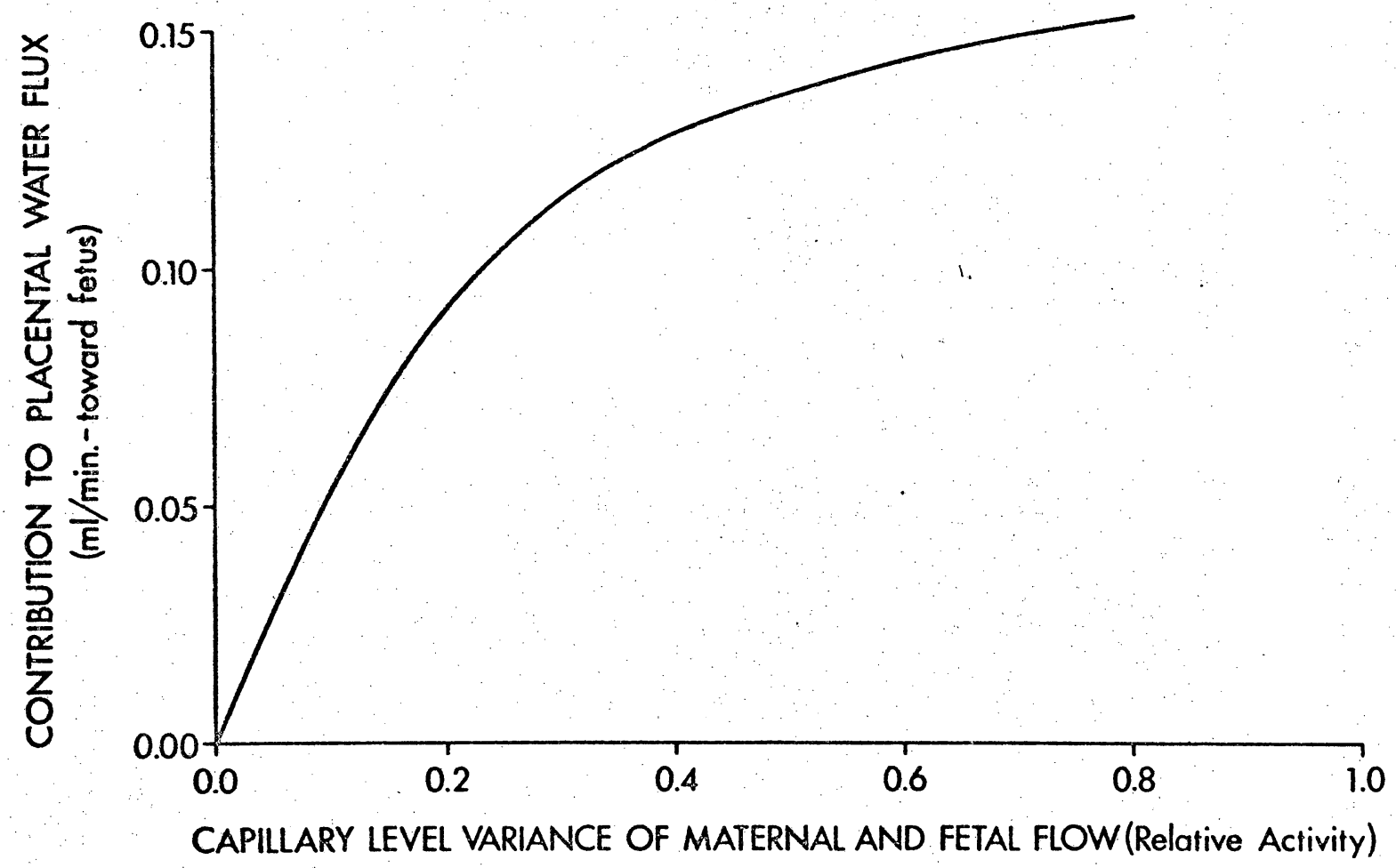

FIGURE 10 
(A)

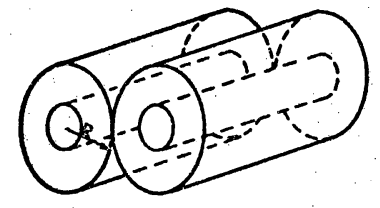

(B)

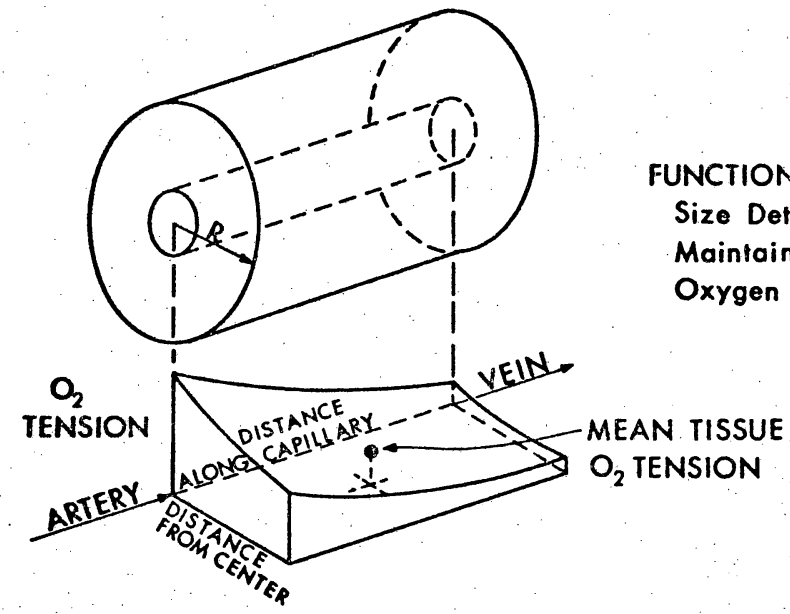

(c)

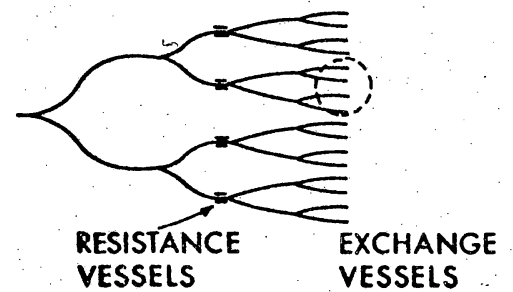

ANATOMIC UNIT

Size Determined by Intercapillary Spacing
REGULATORY UNIT
Region Containing Daughter Branches of a
Vessel whose Resistance, Size and Response to
Control Stimuli May Vary
NCTIONAL UNIT Mainlain a Specified Mean Tissue 

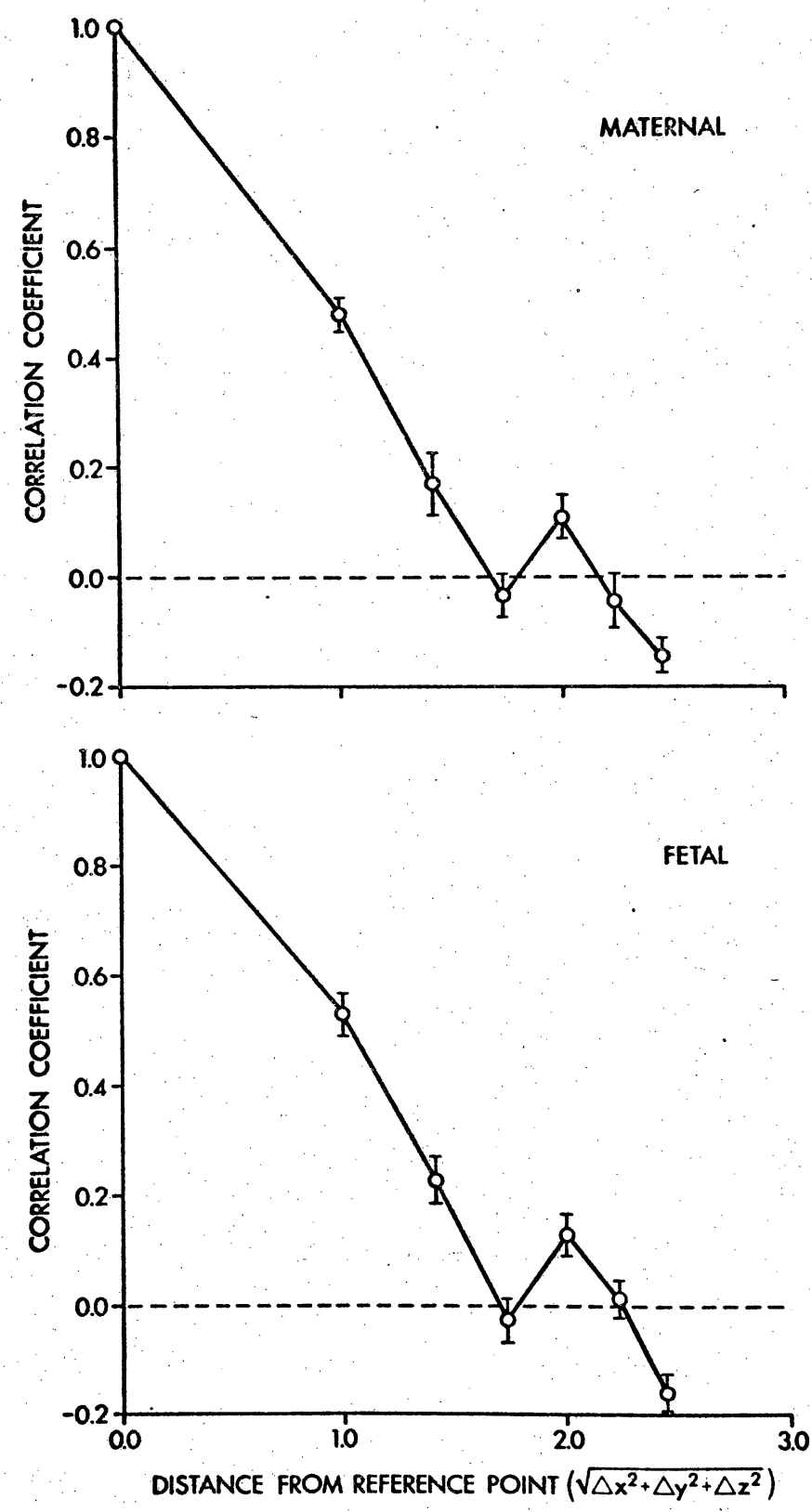

FIGURE 12 